\title{
Capsule Commentary on Rigotti et al., Interactive Voice Response Calls to Promote Smoking Cessation after Hospital Discharge: Pooled Analysis of Two Randomized Clinical Trials
}

\author{
Steven A. Schroeder, MD \\ Department of Medicine, University of California, San Francisco, San Francisco, CA, USA.
}

$\mathrm{J}$ Gen Intern Med

DOI: $10.1007 / \mathrm{s} 11606-017-4088-9$

(c) Society of General Internal Medicine 2017

$\mathrm{H}$ ospitalization provides a timely, convenient opportunity to help smokers quit. This article is the latest in a series by Rigotti from the Massachusetts General Hospital, testing whether human or automated (interactive voice response; IVR) phone calls post-discharge can increase the chances of quitting. ${ }^{1}$ The answer is yes. In this report, the biochemically confirmed 6-month abstinence rate was 19\%, though the cutoff points of $<10 \mathrm{ng} / \mathrm{ml}$ of cotinine or $<9 \mathrm{ppm}$ of $\mathrm{CO}$ might falsely label a few light smokers as abstinent. Although $19 \%$ might seem low, it far surpasses the unassisted rate of $4 \% .^{2}$ As the authors note, it is hard to disentangle the effect of the calls themselves from the provision of free smoking cessation therapy, but it was clear that more phone calls translated into higher quitting odds.

Three questions arise from this study. First, could the IVR technology persuade reluctant hospitals to do the right thing - track whether discharged smokers have tried to quit and whether they succeeded? In 2012, a four-component Joint Commission Tobacco Cessation Performance Measure Set was offered as one of 14 sets from which U.S. hospitals needed to select four. ${ }^{3}$ With the exception of Veterans Affairs (VA) and Department of Defense hospitals, the tobacco measures were rarely adopted. The alleged reason was the high cost required for one of the tobacco measures - ascertaining smoking status post-discharge. The other 13 performance measure sets were not as labor-intensive, and thus hospitals had a financial incentive to choose them preferentially. Although the cost of the IVR system is unspecified, presumably it is less expensive than hiring a human caller. Furthermore, the incentives for ascertaining post-discharge smoking rates may escalate if the Centers for Medicare and Medicaid Services (CMS) incorporate this step into its hospital reimbursement system, as is likely to happen. Second, what would it take for IVR use for smoking cessation to spread to other hospitals? Third, how can we drive up the use of telephone quitlines, which yield quit rates as high as $30 \%$ but are used by fewer than $2 \%$ of all smokers? ${ }^{4}$ The qualitative responses reported by Rigotti hint at systemic access barriers that make calling the 1-800 QUITNOW number less appealing.

Corresponding Author: Steven A. Schroeder, MD; Department of Medicine, University of California, San Francisco, 3333 California St, Suite 430, San Francisco, CA 94143-1211, USA (e-mail: schroeder@medicine.ucsf.edu).

\section{Compliance with Ethical Standards:}

Conflict of Interest: The author reports no financial conflicts of interest.

\section{REFERENCES}

1. Rigotti NA, Chang Y, Rosenfeld LC, Japuntich SJ, Park ER, Tindle HA, Levy DE, Reid ZZ, Streck J, Gomperts T, Kelley JHK, Singer DE. Interactive voice response calls to promote smoking cessation after hospital discharge: pooled analysis of two randomized clinical trials. J Gen Intern Med. doi:10.1007/s11606-017-4085-Z

2. Fiore MC, Jaen CR, Baker TB, et al. Treating tobacco use and dependence: 2008 update. Clinical Practice Guideline. Executive Summary. Rockville, MD: U.S. Department of Health and Human Services. Public Health Service, 2008

3. Fiore MC, Goplerud E, Schroeder SA. The Joint Commission's new tobacco-cessation measures-will hospitals do the right thing? NEJM 2012;366:1172-74

4. North American Quitline Consortium. Results from the 2015 NAQC Annual Survey of Quitlines. 2015. Available at: http://www.naquitline. org/?page=2015Survey. Accessed May 22, 2017 